\title{
First case report of inducible heart block in Lyme disease and an update of Lyme carditis
}

\author{
Don Walter Kannangara* ${ }^{*}$, Sindhu Sidra and Patel Pritiben
}

\begin{abstract}
Background: Lyme disease (LD), is the most common vector-borne illness in the US and Europe, with predominantly cutaneous, articular, cardiac and neuro-psychiatric manifestations. LD affects all layers of the heart and every part of the conducting system. Carditis is a less common manifestation of LD. Heart block (HB) as the initial and sole manifestation of LD is rare. Inducible HB has never been reported in LD. We report a case of heart block (HB) inducible with exercise and reversible with rest.

Case presentation: A 37-year-old male presented to the emergency department after experiencing two episodes of syncope while at work. He presented, with a heart rate of $57 \mathrm{bpm}$, and the ECG showed sinus bradycardia with first degree AV block. The PR interval was 480 ms (NL 120-200 ms). Physical exam was unremarkable. The cardiologist's initial impression was vaso-vagal attack. He developed high degree AV block during a stress test for the initial work up, which resolved on cessation of exercise. A similar episode while walking in the hallway, resolved at rest. The high degree AV block appeared inducible with exercise and reversible with rest. His Lyme serology was strongly positive. He was treated with ceftriaxone and doxycycline. After completing treatment, the patient had a normal ECG and returned to work without limitations, doing manual labor.

Conclusions: Manifestations of Lyme carditis (LC) vary from asymptomatic and symptomatic electrocardiographic changes and heart block (HB) reversible with treatment, to sudden death. $\mathrm{HB}$ as the sole and initial presentation of $L C$ is rare. There have been no reports of inducible HB in LD. Here we present a case of inducible and reversible high degree $H B$ in a case of $L C$ and an update of literature. Exercise and stress testing should be avoided in suspected cases of $L C$ until resolution of carditis. Lyme carditis should be suspected in individuals with cardiac manifestations in an endemic area, particularly in the younger patients with no other etiology evident.
\end{abstract}

Keywords: Lyme disease, Lyme Carditis, Heart block, Tick(s), Borrelia burgdorferi

\section{Background}

LD is caused by members of the Borrelia burgdorferi sensu lato complex transmitted by Ixodes scapularis and I pacificus in the U.S. The estimated annual incidence in the U.S. is 300,000 . $95 \%$ of reported cases come from 12 Northeastern and 2 North Midwestern states [1]. LC is a rarer manifestation of LD [2]. LC may present with or without other manifestations of LD and could involve all layers of the heart: myocardium [3-7], pericardium $[8,9]$, endocardium [10-13], or pancarditis $[4,14,15]$.

\footnotetext{
* Correspondence: kannangara@att.net

St Luke's University Health Network, Warren Campus, 185 Roseberry Street, Phillipsburg, NJ 08865, USA
}

Myocarditis could be focal [6, 16] or diffuse [14]. Any part of the conducting system could be affected, and conduction blocks of varying degrees (Table 1) are the most common. The incidence of LC varies from $0.2-10 \%$ in different reports $[2,17-20]$. The actual incidence may be higher. A pediatric study of patients with Lyme disease found ECG changes in 29\% [21]. LC could result in acute heart failure [22, 23], cardiogenic shock [23, 24], cardiac arrest [25-27], or sudden cardiac death [15, 28, 29]. We report a case of exercise induced progression of first-degree heart block to high degree AV block, with complete resolution on cessation of exercise, which could be reproduced. The patient made a complete 
Table 1 ECG changes reported in Lyme carditis

First degree heart block [16, 17, 30-33]

Wenckebach phenomenon [17, 34-38] (Mobitz type I)

Mobitz type II [34, 38, 39]

Complete Heart block / High degree AV block $[17,25,30,32,34,40-48]$

Bundle branch block $[26,44,49]$

Sinus arrest / Sinus pauses $[22,50,51]$

Supraventricular tachycardia [6]

Atrial fibrillation [16, 44]

Junctional tachycardia [27, 52, 53]

Fascicular tachycardia $[26,41]$

Ventricular tachycardia $[22,25,54]$

Ventricular flutter [22]

Bradycardia [16, 30, 37, 38, 42, 55]

Narrow QRS escape rhythm [34]

Prolonged QT [56, 57]

ST depression / T inversion [30, 57]

ST elevation [58]

Asystole [26]

History of Wolf Parkinson White Syndrome In a case of sudden death due to LC [14]
Steere et al. (1980,1984), Naik et al. 2008, van der Linde (1991), Afari (2016), Tumminello (2017)

Steere et al. (1984), Shah and Kanzaria (2012), Dobbs and Mugmon (2013), Lee and Sigla (2016), Bennett et al. (2016), Muhammad and Simmonelli (2018)

Shah and Kanzaria (2012), Muhammad and Simonelli (2018), Kashou et al. (2018)

Steere et al. (1980,1984), van der Linde (1990), Greenberg et al. (1997), Kline (2007) Bacino et al. (2011), Shah and Kanzaria 2012, Wenger et al. (2012), Dobbs and Mugman (2013), Jensen et al. (2014), Shah et al. (2015), Afari (2016), Timmer (2016), Afari (2016), Lee and Singla (2016), Chaudhry et al. (2017), Patel (2017)

Khalil et al. (2015), Wenger et al. (2012), Cunha et al. (2017)

Franck and Wollschläger (2003), Koene et al. (2012), Oktay et al. (2015)

Konopka et al. (2013)

Naik et al. 2008, Wenger et al. (2012)

Tanksley and Playe (2005), Frank et al. (2011), Cunningham et al. (2016)

Greenberg et al. (1997), Khalil et al. (2015)

Vlay et al. (1991), Koene et al. (2012), Jensen et al. (2014)

Koene et al. (2012)

Steere et al. 1980, Kline (2007), Naik et al. 2008, Abraham et al. (2010), Bennett et al. (2016) Muhammad and Simonelli (2018)

Shah and Kanzaria (2012)

Seslar et al., (2006), Welsh et al. (2012)

Steere et al. (1980), Welsh et al. (2012)

Michalski et al. (2017)

Khalil et al. (2015)

CDC (2013)

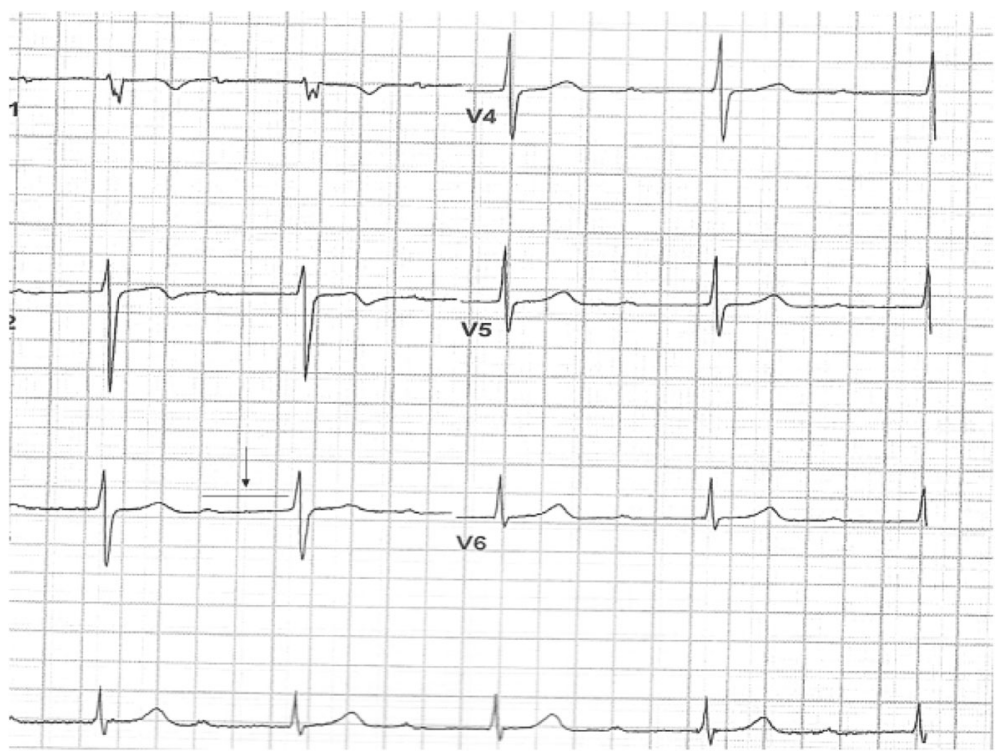

Fig. 1 Admission ECG showing first degree heart block ( $P R=480 \mathrm{~ms})$ 


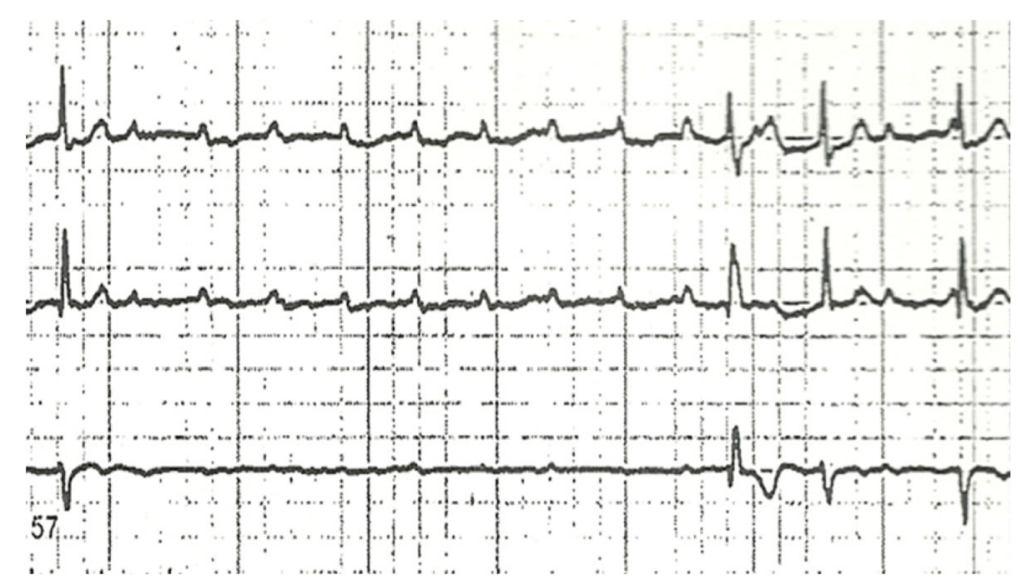

Fig. 2 High degree A-V block during exercise

recovery after treatment with intravenous ceftriaxone and doxycycline.

\section{Case presentation}

A 37-year-old male with past medical history significant for asthma, anxiety, and former tobacco use, presented to our emergency department after experiencing two episodes of syncope while at work. He was employed outdoors in a heavy manual labor industry. He and his co-workers have been frequently bitten by ticks at work in the past. Initial vital signs on admission were significant for bradycardia, with a heart rate of 57 bpm, and the ECG showed sinus bradycardia with first degree AV block, with a PR interval of $480 \mathrm{~ms}$ (NL 120-200 ms) (Fig. 1). Physical exam was unremarkable, except for hypopigmentation of fingers. Serum ALT level was elevated 115 (NL 12-78). Other labs on admission were all within normal including serum troponin. Further workup included a normal CT scan of head, a vascular study of the carotid vessels that showed minor right sided carotid stenosis of $<50 \%$, and an echocardiogram that was unremarkable,except for mildly increased LV wall thickness with an EF of $60 \%$. An exercise stress test done by the cardiologist, was terminated early. The patient developed dyspnea, and his ECG demonstrated progression of first-degree AV block to high degree AV block (Fig. 2). Once back at rest, the patient's high degree AV block reverted to first degree AV block. He had a similar episode while walking in the hallway wearing a Holter monitor, on day 5, also reversible with rest. He was transferred to the critical care unit for close monitoring and treated with ceftriaxone $2 \mathrm{G}$ iv once daily and doxycycline $100 \mathrm{mg}$ orally twice daily. The first-degree AV block improved with a gradual decrease in the PR interval (Table 2). His Lyme serology (Western Blot) was strongly positive (Table 3 ).
The heart block significantly improved to $270 \mathrm{~ms}$ by day 7 of treatment. He was discharged and continued outpatient IV Ceftriaxone for 3 weeks. After completing treatment, the patient had a normal ECG with PR interval of 178 (Fig. 3) on day 16 and an uneventful exercise stress test. He returned towork without limitations, doing manual labor. He has been symptom free for 2 years. Now he uses tick-repellents at work.

\section{Discussion and conclusions}

Cardiac involvement has been reported with B.burgdorferi ss (US cases), B garinii, B afzelli [12] and $B$ bissettii [10]. Patients with $\mathrm{CHB}$ (Complete heart block) due to LC may have erythema migrans [32, 36, 37, 47, 48, 58] or other manifestations such as joint involvement [8]. Basic investigations include the history of possible tick exposure, laboratory testing, a 12-channel electrocardiogram, 24-h Holter monitor, chest $\mathrm{x}$-ray, and echocardiography [2]. The two-tier antibody-based test recommended by the $\mathrm{CDC}$ is highly specific but has poor sensitivity [59]. Supplementary studies that have been used in the diagnosis include echocardiography [7, 57, 60], gadolinium enhanced cardiac MRI [16, 27], endo-myocardial biopsy $[6,7,22,61,62]$ with special staining [3, 4, 8, 40], culture [3] or electron microscopy [7, 61-63], Ga67 Scan [64-66], and Indium 111 labelled anti-myosin antibody scintigraphy [4]. Histology of affected cardiac tissue shows infiltration predominantly with lymphocytes and plasma cells [15, 22, 29, 40].

Progression of first-degree heart block to second degree and then to complete heart block without treatment has been reported. Regression of complete heart block

Table 2 PR interval decrease with treatment

\begin{tabular}{lllllll}
\hline DAY & 1 & 4 & 5 & 6 & 7 & 16 \\
PR Interval & 480 & 416 & 440 & 316 & 284 & 178 \\
\hline
\end{tabular}


Table 3 Lyme serology results

\begin{tabular}{ll}
\hline Lyme AB IGG & $2.3(0.00-0.79)$ \\
Lyme AB IGM & $15.67(0.00-0.79$ \\
Lyme $18 \mathrm{kD}$ lgG & Present \\
Lyme $23 \mathrm{kD} \operatorname{lgG}$ & Present \\
Lyme $30 \mathrm{kD} \operatorname{lgG}$ & Present \\
Lyme $39 \mathrm{kD} \operatorname{lgG}$ & Present \\
Lyme $41 \mathrm{kG}$ lgG & Present \\
Lyme $45 \mathrm{kG}$ lgG & Present \\
Lyme $58 \mathrm{kG}$ igG & Present \\
Lyme $23 \mathrm{kD} \operatorname{lgM}$ & Present \\
Lyme $39 \mathrm{kD} \operatorname{lgM}$ & Present \\
Lyme $41 \mathrm{kD} \operatorname{lgM}$ & Present \\
\hline
\end{tabular}

to second degree, then first degree followed by complete resolution with treatment is also known [32]. Inducible heart block in Lyme disease has not been reported. We present the first report of inducible heart block in a patient whose initial and sole manifestation of LD was HB. First-degree heart block worsened to high degree AV block on exercise, which was reversible with rest and reproducible during the hospitalization.

As illustrated in this case, exercise and stress testing should not be carried out in LD patients until complete recovery from heart block. HB secondary to Lyme disease rarely requires a permanent pacemaker. However, patients with a PR interval greater than 300 $\mathrm{ms}$ should be monitored in an intensive care setting, as they may rapidly progress to complete $\mathrm{HB}$ [30]. A temporary pacer is sometimes required; however, most patients respond to treatment within two to three weeks. The antibiotics used in LC include amoxicillin [12], ceftriaxone $[8,9,32,36,38,41,53]$, doxycycline [49] and ceftriaxone and doxycycline [13, 37]. Duration of treatment varied from 2 weeks to one month.

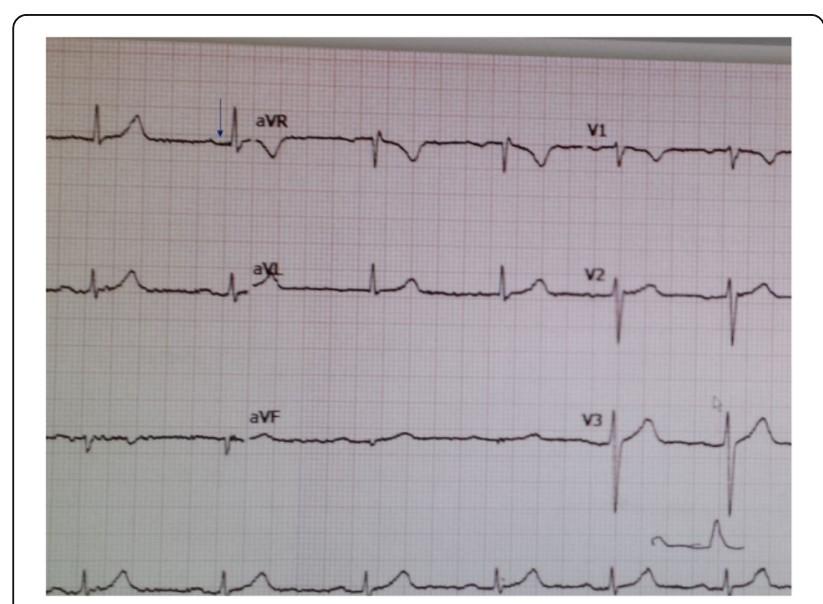

Fig. 3 ECG after treatment showing normal PR interval ( $P R=178 \mathrm{~ms}$ )
LC may present with $\mathrm{HB}$ as the sole [53] or initial presentation $[45,66]$ with or without other manifestations of LD [30, 32, 36, 37, 48] or with multiple electrocardiographic (Table 1) and clinical presentations. First degree $\mathrm{HB}$ is the most common manifestation, which could rapidly progress to $\mathrm{CHB}$ [32]. It is important to keep a high degree of suspicion for Lyme disease in endemic areas in patients with cardiac symptoms with or without other manifestations of LD, particularly younger individuals with no other etiology evident. Some patients with complete heart block may need a temporary pacemaker [26, 39, 47, 55, 66, 67]. The majority of AV blocks in $\mathrm{LC}$ are reversible with antibiotic treatment. Exercise is contraindicated until resolution of LC.

\section{Abbreviations \\ ALT: Alanine aminotransferase; AV: Atrioventricular; BPM: Beats per minute; CDC: Center for disease control; CHB: Complete heart block; CT: Computed tomography; ECG: Electrocardiogram; EF: Ejection fraction; HB: Heart block; IGG: Immunoglobulin G; IGM: Immunoglobulin M; IV: Intravenous; LC: Lyme carditis; LD: Lyme Disease; LV: Left ventricle; MRI: Magnetic resonance imaging; MS: Milli seconds; NL: Normal limits}

\section{Acknowledgements}

We acknowledge the assistance of Dr. Amit Prasad, MD and Dr. Renu Toshniwal, MD for involvement in patient care.

\section{Funding}

No funding was received for the study.

\section{Availability of data and materials}

All data generated or analysed during this study are included in this published article. Additional data analysed during the current study are available from the corresponding author on reasonable request.

\section{Authors' contributions}

Patient management (DWK), preparing case report (SS, DWK, PP), tables (DWK), figures (DWK, SS, PP) literature review (DWK), and preparing manuscript and references (DWK, SS, PP). All authors have read and approved the manuscript.

\section{Ethics approval and consent to participate}

Approved by St Luke's University Health Network (SLUHN) Institutional Review Board Exempt study 2018-113.

\section{Consent for publication}

Written Informed consent was given by patient and wife for publication of this case report with Lyme test results and ECG findings.

\section{Competing interests}

All authors have no financial disclosures or competing interests.

\section{Publisher's Note}

Springer Nature remains neutral with regard to jurisdictional claims in published maps and institutional affiliations.

Received: 8 February 2019 Accepted: 25 April 2019

Published online: 16 May 2019

\section{References}

1. CDC. 2017. Lyme statistical tables. www.cdc.gov/lyme/stats/tables.html

2. Scheffold N, Herkommer B, Kandolf R, May AE. Lyme Carditis. Dtsch Arztebl. 2015;112:202-8.

3. Klein J, Stanek G, Bittner R, Horvat R, et al. Lyme borreliosis as a cause of myocarditis and heart muscle disease. Eur Heart J. 1991;12 Suppl D:73-5. 
4. Bergler-Klein J, Ullrich R, Glogar D, Stanek G. Lyme borreliosis and cardiomyopathy. Wien Med Wochenschr. 1995;145:196-8.

5. Cepelová J. Lyme carditis — rare cause of dilated cardiomyopathy and rhythm disturbances. Vnitr Lek. 2008;54:430-3.

6. Konopka M, Kuch M, Braksator W, Walczak E, et al. Unclassified cardiomyopathy or Lyme carditis? A three-year follow-up. Kardiol Pol. 2013;71:283-5

7. Plocarová K. Inflammatory Borrelia - associated dilated cardiomyopathy. Vnitr Lek. 2013;59:1107-10.

8. Bruyn GAW, Koning JDE, Reijsoo PM, Hoogkamp-Korstanje JAA. Lyme pericarditis leading to tamponade. Rheumatology. 1994;33:862-6.

9. Gasser R, Horn S, Reisinger E, Fischer L, et al. First description of recurrent pericardial effusion associated with Borrelia burgdorferi infection. Int J Cardiol. 1998;64:309-10.

10. Rudenko N, Golovchenko M, Mockráček A, Piscunová N, et al. Detection of Borrelia bissettii in cardiac valve tissue of a patient with endocarditis and aortic valve stenosis in the Czech Republic. J Clin Microbiol. 2008;46:3540-3.

11. Kameda G, Vieker S, Hartmann J, Niehues T, et al. Diastolic heart murmur, nocturnal back pain, and lumbar rigidity in a 7-year old girl: an unusual manifestation of Lyme disease in child hood. Case Rep Pediatr. 2012;2012: 976961.

12. Hidri N, Barraud O, de Martino S, Garnier F, et al. Lyme endocarditis. Clin Microbiol Infect. 2012;18:E531-2.

13. Patel LD, Schachne JS. Lyme carditis: a case involving the conduction system and the mitral valve. R I Med J. 2017;100:17-20.

14. CDC morbidity and mortality report (MMWR). Three sudden cardiac deaths associated with Lyme carditis, vol. 62; 2013. p. 993-6.

15. Yoon EC, Vail E, Kleinman G, Lento PA, et al. Lyme disease: a case report of a 17- year-old male with fatal Lyme carditis. Cardiovasc Pathol. 2015;24:317-21.

16. Naik M, Kim D, O'Brien F, Axel L, et al. Lyme carditis. Circulation. 2008;118:1881-4.

17. Steere AC, Malawista SE, Bartenhagen NH, Spieler PN, et al. The clinical spectrum and treatment of Lyme disease. Yale J Biol Med. 1984;57:453-61.

18. Hofthuis A, Arend SM, Davids CJ, Tukkie R, et al. General practitioner reported incidence of Lyme carditis in the Netherlands. Neth Heart J. 2015;23:533-8

19. Robinson ML, Kobayashi T, Higgins $Y$, Calkins H, et al. Lyme carditis. Infect Dis Clin N Am. 2015;29:255-68.

20. Kwit NA, Nelson CA, Max R, Mead PS. Risk factors for clinician-diagnosed Lyme arthritis, facial palsy, carditis, and meningitis in patients from highincidence states. Open Forum Infect Dis. 2017;5:ofx254.

21. Woolf PK, Lorsung EM, Edwards KS. Electrocardiographic findings in children with Lyme disease. Pediatr Emerg Care. 1991;7:334-6.

22. Koene R, Boulware DR, Kemperman M, Konety SH, et al. Acute heart failure from Lyme carditis. Circulation. 2012;5:e24-6.

23. Župan Ž, Mijatović D, Medved I, Kraljić S, et al. Successful treatment of fulminant Lyme myocarditis with mechanical circulatory support in a young male adult: a case report. Croat Med J. 2017:58:185-93.

24. Clinckaert C, Bidgoli S, Verbeet T, Attou R, et al. Peri-operative cardiogenic shock suggesting acute coronary syndrome as initial manifestation of Lyme carditis. J Clin Anesth. 2016;35:430-3.

25. Jensen TB, Dalsgard D, Johansen JB. Cardiac arrest due to torsades pointes ventricular tachycardia in a patient with Lyme carditis. Ugeskr Laeger. 2014; 25:176(35)

26. Khalil S, Padala SK, Hui CM, Steckman DA, et al. Lyme carditis in the fast lane: from alternating bundle branch block to asystole in 12 hours. Conn Med. 2015;24:317-21.

27. Cunningham MEA, Doroshow OL, Moak JP. Junctional ectopic tachycardia secondary to myocarditis associated with sudden cardiac arrest. Heart Rhythm case Rep. 2016;3:124-8.

28. Cary NRB, Fox B, Wright DJ, Cutler SJ, et al. Fatal Lyme carditis and endodermal heterotopia of the atrioventricular node. Postgrad Med. 1990;66:134-6

29. Muehlenbachs A, Bollweg BC, Schultz TJ, Forrester JD, et al. Cardiac tropism of Borrelia burgdorferi: an autopsy study of sudden cardiac death associated with Lyme carditis. Am J Pathol. 2016;186:1195-205.

30. Steere AC, Batsford WP, Weinberg WP. Lyme carditis: cardiac abnormalities of Lyme disease. Ann Int Med. 1980;93:8-16.

31. Van der Linde MR. Lyme Carditis: clinical characteristics of 105 cases. Scand J Infect Dis Suppl. 1991;77:81-4.
32. Afari ME, Marmoush F, Rehman MU, Gorsi U, et al. Lyme carditis: an interesting trip to third degree heart block and back. Case Rep Cardiol. 2016;2016:5454160.

33. Tumminello R, Glaspey L, Bhamidipati A, Sheehan P, Patel S. Early disseminated Lyme disease masquerading as mononucleosis: a case report. J Emerg Med. 2017;53:e133-5.

34. Shah R, Kanzaria M. A case series of Lyme carditis complete heart block. The Medicine Forum. 2012;13:article 4.

35. Dobbs LB, Mugmon MA. Wenckebach responsive to cephalosporins- it must be Lyme carditis. J community Hosp Intern Med Perspect. 2013;3:3-4.

36. Lee $\mathrm{S}$, Singla M. An unrecognized rash progressing to Lyme carditis: important features and recommendations regarding Lyme disease. Am J Ther. 2016:23(2):e566-9.

37. Bennett KM, Jehangir A, Fadahunsi O, Rettew A, et al. Bulls-eye marks the spot: Lyme carditis presenting as rash and presyncope. [abstract]. Hospital Medicine. 2016;11(suppl 1). https://www.shmabstracts/bulls-eye-marks-thespot-lyme-carditis-presenting-as-rash-and-presyncope.

38. Muhammad S, Simonelli RJ. Lyme Carditis: a case report and review of management. Hosp Pharm. 2018; https://doi.org/10.1177/0018578717749927.

39. Kashou AH, Braiteh $\mathrm{N}$, Kashou HE. Reversible atrioventricular block and the importance of close follow-up: two cases of Lyme carditis. J Cardiol Cases. 2018;17:171-4.

40. Van der Linde MR, Crijns HJ, de Koning J, Hoogkamp-Korstanje JA, et al. Range of atrioventricular conduction disturbances in Lyme borreliosis: a report of four cases and review of other published reports. Br Heart J. 1990;63:162-8.

41. Greenberg YJ, Brennan JJ, Rosenfeld L. Lyme myocarditis presenting as fascicular tachycardia with underlying complete heart block. J Cardiovasc Electrophysiol. 1997:8:323-4.

42. Kline AM. Bradycardic child: what is to blame? J Pediatr Health Care. 2007;21:399-400.

43. Bacino L, Gazzarata M, Siri G, Cordone S, et al. Complete atrioventricular block as the first clinical manifestation of a tick bite (Lyme disease). G Ital Cardiol (Rome). 2011;12:214-6.

44. Wenger N, Pellaton C, Bruchez P, Schläpfer J. Atrial fibrillation, complete atrio-ventricular block and escape rhythm with bundle-branch block morphologies: an exceptional presentation of Lyme carditis. Int J Cardiol. 2012;160:e12-4

45. Shah P, Mithwala P, Bajaj S, Virk H, et al. Third-degree heart block as initial presentation of Lyme disease. Acta Cardiol. 2015;70:744-5.

46. Timmer SAJ, Boswijk DK, Kimman GP, Germans T. A case of reversible thirddegree AV block due to Lyme carditis. J Electrocardiol. 2016;49:519-21.

47. Chaudhry MA, Satti SD, Friedlander IR. Lyme carditis with complete heart block: management with an external pace maker. Clin Case Rep. 2017:5:915-8.

48. Patel KP, Farjo PD, Juskowich JJ, Hama AA, et al. Early-onset Lyme carditis with concurrent disseminated erythema migrans. Am J cardiovasc Dis. 2017;7:53-6.

49. Cunha BA, Elyasi M, Singh $P$, Jimada I. Lyme carditis with isolated left bundle branch block and myocarditis successfully treated with oral doxycycline. I D cases, vol. 11; 2017. p. 48-50.

50. Franck $\mathrm{H}$, Wollschläger $\mathrm{H}$. Lyme carditis and symptomatic sinus node dysfunction. Z Kardiol. 2003:92:1029-32.

51. Oktay AA, Dibs SR, Friedman H. Sinus pause in association with Lyme carditis. Texas Heart Inst J. 2015;42:248-50.

52. Tanksley GW, Playe SJ. Lyme carditis: from asymptomatic first-degree heart block to dilated cardiomyopathy. Emerg Med News. 2005;27:14-6.

53. Frank DB, Patel AR, Sanchez GR, et al. Junctional tachycardia in a child with Lyme carditis. Pediatr Cardiol. 2011;32:689-91.

54. Vlay SC, Pervan JP, Elias J, Kane PP, et al. Ventricular tachycardia associated with Lyme carditis. Am Heart J. 1991;121:1558-60.

55. Abraham S, Reddy S, Abboud J, Jonnalagadda K, et al. Brief, recurrent, and spontaneous episodes of loss of consciousness in a healthy young male. Int Med Case Rep J. 2010:3:71-6.

56. Seslar SP, Berul Cl, Burklow TR, Cecchin F, et al. Transient prolongation of QT interval in Lyme disease. J Pediatr. 2006;148:692-7.

57. Welsh EJ, Cohn KA, Nigrovic LE, Thompson AD, et al. Electrocardiographic abnormalities in children with Lyme meningitis. J Pediatric Infect Dis Soc. 2012;1:293-8.

58. Michalski B, Umpierrez De RA. Lyme carditis buried beneath the ST-segment elevations. Case Rep Cardiol. 2017;2017:9157625. 
59. Kannangara DW, Patel P. Report of non-Lyme erythema migrans rashes from New Jersey with a review of possible role of tick salivary toxins. Vector borne Zoonotic dis. 2018;18:641-52.

60. Vujisić-Tesić B, Simin N, Petrović M, Vasiljević Z, et al. The role of echocardiography in the evaluation of cardiac damage in Lyme disease. Glas Srp Akad Nauka Med. 1993:43:241-3.

61. Palacek T, Kuchynka P, Hulinska D, Schramlova J, et al. Presence of Borrelia burgdorferi in endomyocardial biopsies in patients with new-onset unexplained dilated cardiomyopathy. Med Microbiol Immunol. 2010;199:139-43.

62. Kubánek M, Šramko M, Berenová D, Hulinská D, et al. Detection of Borrelia burgdorferi sensu lato in endomyocardial biopsy specimens in individuals with recent-onset dilated cardiomyopathy. Eur J Heart Fail. 2012;14:588-96.

63. Lalosevic D, Lalosevic V, Stojsic-Milosavljevic A, Stojsic C. Borrelia-like organism in heart capillaries of patient with Lyme disease seen by electron microscopy. Int J Cardiol. 2010;145:e96-8.

64. Alpert LI, Welch P, Fischer N. Gallium-positive Lyme disease myocarditis. Clin Nucl Med. 1985;10:617

65. Veluvolu P, Balian AA, Goldsmith R, Gallant TE, et al. Lyme carditis. Evaluation by GA-67 scan and MRI. Clin Nucl Med. 1992;17:823.

66. Kimball SA, Janson PA, L Raia PJ. Complete heart block as the sole presentation of Lyme disease. Arch Int Med. 1989:149:1897-8.

67. Isath A, Padmanabhan D, Naksuk N, Kella D, et al. Europace. Leadless pacemaker used as long- term temporary therapy in Lyme carditis with high-grade atrioventricular block; 2018.

https://doi.org/10.1093/eurospace/euy175

Ready to submit your research? Choose BMC and benefit from:

- fast, convenient online submission

- thorough peer review by experienced researchers in your field

- rapid publication on acceptance

- support for research data, including large and complex data types

- gold Open Access which fosters wider collaboration and increased citations

- maximum visibility for your research: over $100 \mathrm{M}$ website views per year

At $\mathrm{BMC}$, research is always in progress.

Learn more biomedcentral.com/submissions 